OPERANT CONDITIONING

OF VASOCONSTRICTION

by

CHARLES WINKLER SNYDER

B.M.E., University of Wichita, 1951

A MASTER'S THESIS

submitted in partial fulfillment of the

requirements for the degree

MASTER OF SCIENCE

Department of Psychology

KANSAS STATE UNIVERSITY

Manhattan, Kansas

1967

Approved by:

$\frac{\text { Meinill \&. Moble }}{\text { Major Prosessor }}$ 
CONTENTS

Introduction ..................... 1

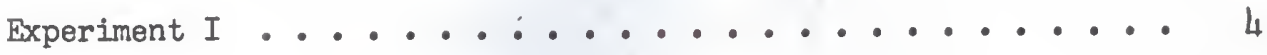

Method

Subjects .................... 4

Apparatus ....................... 4

Procedure .................... 5

scoring ..................... 6

Results

Conditioned vasoconstrictions .......... 8

Respiration control ............ 10

Thermal stimuli control ............. 11

Activation level control ........... 11

Discussion .................. Il

Experiment II . . . . . . . . . . . . . 12

Method

Design ............... 15

Subjects .............. 15

Apparatus ................. 16

Procedure ................. 18

Scoring ............... 19

Results

Vasoconstriction conditioning . . . . . . . 22

Vasoconstriction extinction . . . . . . . 25

Vasomotor response to reinforcement . . . . . . 27

Respiratory control and conditioning . . . . . 29 


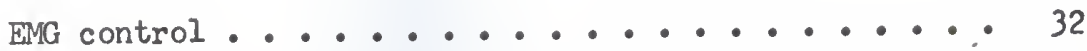

General activation level control ........ 34 MAS scores ....................... 34 Interview .............. 37

Discussion ................ 37 Acknowledgement ......................... 42 References ......................... 43 


\section{OPERANT CONDITIONING OF VASOCONSTRICTION}

Since Skinner's (1938) mention of an unsuccessful attempt to obtain operant conditioning of vasoconstriction, several reports of operant conditioning of autonomic activity have appeared. Razran (1961) reported an experiment by Lisina (1958) in which vasoconstriction was transformed into vasodilation when subjects could watch their record and note the connection between vasodilatation and shock termination. Cognitive mediation was also employed by Shearn (1962) in operant conditioning of heart rate; heart beats were audible to the subject over a loudspeaker. When such direct mediation has not been provided, operant conditioning has been observed by Fowler and Kimmel (1962) with the galvanic skin response (GSR). However, their curves did not show an increase in GSR frequency resulting from the operant procedure; instead, performance remained relatively constant in the experimental group while it decreased in the control group. Presumably, adaptation occurred in both groups. In a later study, Kimmel and Kimmel (1963) obtained an initial brief rise during conditioning but again followed by adaptation. However, Crider, Shapiro, and Tursky (1966) found longterm incremental GSR operant conditioning in an experimental group that had an initially low operant level. Apparently, a control on general activation level is necessary (as in the latter experiment) to isolate specific from nonspecific adaptation effects.

In another species, Fromer (1963) reported a series of three experiments with volume changes in the ear of rabbits, comparing discriminant operant conditioning with classical conditioning, using negative reinforcement (electric shock). Performance improved under all condi- 
tions, but there was greater resistance to extinction in the discriminant operant than with classical conditioning.

Historically, the theoretical significance of autonomic conditioning, and vasomotor in particular, may be traced back to Lange's (1885) theory of emotion. Lindsley (1951) states:

Lange's theory, put forth independently, held that a stimulus object or situation gives rise immediately to vasomotor changes wherever blood vessels are found. The secondary changes occurring in the tissues were believed to give rise to the sensations that constitute the emotion. More recent interpretations of Lange's theory have recognized that the sensory impulses may arise from receptors in the blood vessels themselves (p. 501).

There have been some impressive demonstrations of vasomotor conditioning and "voluntary" control (Kennard, 1937; Lisina, 1958). All lack some of the necessary controls (Shmavonian, 1959), but apparently vasomotor classical conditioning and control (by the subject's own verbal mediation, established by classical conditioning) is possible. Berlyne (1960) stresses the significance of orienting responses (Sokolov, 1963) which are probably involved here.

But classical conditioning procedures do not appear to be providing the answer to the problem of how vasomotor activity normally affects behavior. Lacey (1958) has stated that "...feedback via visceral afferents and reticular formations, or via the baroreceptors, implies that an autonomic response becomes a stimulus" (p. 202). But a series of experiments on autonomic feedback in perceptual learning (Snyder, 1960), based on two-factor learning theory, gave inconclusive results. The most likely difficulty was that "... in general the very long reaction times of autonomic responses make it difficult to use sensory signals, which feed back from these responses, as CSs which serve as cues 
for perceptual acts" (Solley and Murphy, 1960, p. 251).

Skinner's dictum - that "There is little reason to expect operant conditioning of autonomic activity since it does not as a rule naturally act upon the environment in any way that will produce a reinforcement..." (1938, p. 112) - seems to apply very well in the case of GSR. But the general hypothesis being considered here is that vasomotor operant conditioning could very well be involved in the contact with the environment, i.e., that certain patterns of autonomic activity may be negatively or positively reinforced by stimulus objects in the environment via the autonomic effect upon selective attention.

Within this framework of the general problem, two experiments were performed to investigate the operant conditioning of finger vasoconstrictions in human subjects, with controls for possible mediation by skeletal musculature including body movements and respiration.

In the first experiment, reinforcement was given in the context of a pseudo-task of discriminating small temperature changes in the finger. The purpose of the pseudo-task was to provide a reason for the brief light signal that served as reinforcement and to focus the subject's attention on the finger but away from the response being conditioned. There were controls for possible mediation of vasoconstriction by the signal light, by the thermal stimuli, and by verbal reports of temperature discriminations.

In the second experiment, the control problem was simplified by eliminating the thermal stimuli and verbal reports, and direct controls were taken on skeletal muscle tension and respiration by separate oscillographic recording. An extinction procedure was also added, with experimental subjects divided into two extinction conditions. 
Experiment I

Method

Subjects. A total of 24 students from introductory psychology classes were used, 5 males and 7 females in each of two groups. Subjects received course credit for participation. 'Three additional subjects were excluded from the results: one because of insufficient time, one because of no detectable finger volume changes, and one because a finger tic produced very large movement artifacts.

Apparatus. Finger volume changes were recorded with a Yellow Springs-Fels plethysmograph on one channel of a Sanborn Model 320 Dual Channel DC Amplifier-Recorder at $1 \mathrm{~mm} \cdot / \mathrm{sec}$. speed. Preliminary tests indicated that thermostatic control of finger temperature was unnecessary for the present purposes: changes of $3^{\circ} \mathrm{C}$. produced only a slow change of $1 \mathrm{~mm}$. in the record, too small and slow to be confused with vasoconstrictions. Instead, the Yellow Springs Model 73 Tele-Thermometer was used for temperature stimulation and recording (on the other Sanborn channel) with the subject's right index finger tip resting lightly on the temperature probe tip in the plethysmograph water cup. The subject was located in a separate sound-treated room, seated in a dental chair in front of a table containing a large white viewing box in the shape of a hemicylinder. The right arm was on an arm rest with the index finger in the plethysmograph cup. The finger was approxtmately at heart level and at the water line of the plethysmograph standpipe. The reinforcement light was an NE-5l neon lamp in a standard neon light assembly with frosted white plastic dome located in the center of the screen at eye level. The neon lamp was operated at 0.1 watt 
for 1-sec. duration from a Tektronix Model 162 Waveform Generator and an external 40-V. fixed supply, and recorded on one Sanborn marker channel. At the 2-ft. viewing distance the signal light illuminance measured $0.001 \mathrm{ft.-candle}$ on a Photovolt Model 501-M Electronic Photometer (with a Type B phototube). Room illumination consisted of a 25-watt ceiling lamp and 20-watt fluorescent lamp in the viewing box.

The experimenter and most of the equipment were located in an adjoining room. Verbal reports of temperature discriminations were heard over an intercom and recorded on a second Sanborn marker channel by the experimenter.

Procedure. After the subject was seated and the apparatus adjusted, the following instructions were read:

This is an experiment in judging very small temperature changes in the finger tip. I will put this plastic cup on your right index finger and it will be filled with water. In this device there are means of slightly warming or cooling the water surrounding your finger and also a pickup to record the temperature changes on a recorder. This is also very sensitive to finger movements, so during the experiment try not to move this finger any more than absolutely necessary (show record of movement artifact). Your finger should be resting lightly on the end of the plug in the cup at all times. For the same reason, please try to relax as comfortably as possible in one position and don't make any kind of movement unnecessarily during the experiment.

In this experiment, we will be measuring how accurately you can detect small changes in finger temperature. Whenever you feel a slight increase in temperature, report "warmer" - I can hear you over this intercom - and whenever you feel a slight decrease in temperature, say "cooler." During the first five minutes we'Il simply determine how you do at this without practice. You can probably do best if you can find a comfortable posture, relax all your muscles as completely and generally as possible, breath quietly and evenly, and don't use any more energy than necessary in giving your reports. After this there will be a one-minute rest when you will be free to move around without upsetting the recording. Do you have any questions?

A five-minute period of operant vasomotor activity with no reinforcement was then recorded. During this time, differential tempera- 
ture discrimination was measured by the Method of Limits. Since the temperature stimulation was controlled by turning on or off the plethysmograph cup heater, the average starting point $\left(36^{\circ} \mathrm{C}\right.$.) had to be above normal finger skin temperature (about $32^{\circ} \mathrm{C}$. ). Different starting points and a pseudo-random order of stimulation were given.

During the one-minute rest period that followed, the reinforcement criterion of vasoconstriction - 50 per cent of average baseline amplitude - was estimated from inspection of the plethysmograph recording. Then the training instructions were given:

Now we want to see how much you can improve your judgment by training. Continue to make your reports of "warmer" and "cooler," and I will signal you when you are correct by flashing on the little light in front of you. It's also important that you do not report a change when there is no change so I may occasionally flash the light on to signal that you are correct by not reporting any change at all. (A necessary instruction since vasoconstriction reinforcements would seldom follow verbal reports, especially in the control group.) So any flash of the light means that you are correct. Try to report even the slightest change and don't be afraid to guess when you are not sure. Remember to relax as much as possible, breath quietly and evenly, and don't use any more. energy than necessary in giving your verbal reports. Do you have any questions?

Then followed a 30-minute experimental period. with subjects in Group E receiving 100 per cent reinforcement (light signal of "correct") of all vasoconstrictions reaching 50 per cent of average baseline amplitude.

Control subjects, matched in sex, age, instructions, and in number of reinforcements in each minute, differed from their corresponding experimental subjects only in being given the light signal after five seconds of essentially zero fluctuation in finger volume.

Scoring. Oscillographic records were scored using a more rigorous procedure than was possible during training in determining those 
responses to be reinforced. Now, instead of merely determining. whether or not the amount of change exceeded 50 per cent of the baseline change, four criteria were used. First, the required amplitude was determined for each subject so as to exclude changes that could be attributed to respiration or pulse (see Burch, Cohn, and Neumann, 1942, for illustrations of these changes). In all instances, the amount of change was greater than 50 per cent of the mean baseline change, and in most instances was closer to 90 per cent of the mean baseline change? Second, responses were restricted to those in which the peak amplitude of vasoconstriction occurred within 10 seconds after the initial deflection of the galvanometer, in order to include characteristic vasoconstrictions but to exclude slow drifts in the vasomotor waves. Third, all movement artifacts produced by rapid movement of the finger or body (as indicated by abrupt irregularities in the plethysmograph record) were excluded. And fourth, all criterion vasoconstrictions that began 0-6 seconds following a verbal report by the subject of a change in temperature were excluded, even though these had been reinforced for subjects in Group E. Such vasoconstrictions amounted to about 40 per cent of all criterion vasoconstrictions during the 30-minute training period for both groups and remained evenly distributed across all periods. This verbal response artifact appeared to be a constant factor in both groups since for both groups combined there was an insignificant change in mean number of temperature discriminations from 7.0 in the first

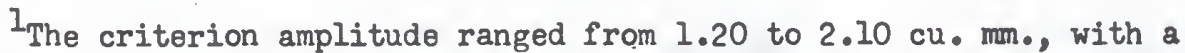
mean of $1.56 \mathrm{cu}$. mm. for Group E; and ranged from 1.05 to $2.25 \mathrm{cu}$. mm., with a mean of $1.75 \mathrm{cu}$. mm. for Group $\mathrm{C}$. The difference between means was not significant $(p>.05)$. 
five-minute period to 7.6 in the last period.

Each response that was scored thus was a vasoconstriction, not related to movement or verbal response artifact, that reached peak amplitude within ten seconds after it was initiated, and that showed gradually decreasing volume together with gradually decreasing pulse amplitude and change in the pulse dicrotic notch.

Results

Conditioned vasoconstrictions. The mean number of vasoconstrictions that met the criteria specified above are shown in Fig. 1. During the baseline period the difference between the means of the experimental and control conditions was negligible $(F=0.006)$. Thereafter, however, the number of vasoconstrictions rose from a mean of 2.0 to a mean of 8.2 by the end of training for the experimental condition. For the control condition, on the other hand, the mean performance remained essentially constant throughout training. The difference between control and experimental condition for all training periods combined was statistically significant by analysis of variance $(F=57.18,1$ \& 11 df, $\mathrm{p}<.001)$

There were large individual differences in conditioning. In Group $\mathrm{E}$, individual subjects reached peaks in frequency of criterion vasoconstrictions ranging from 6 to 14 per five-minute period, corresponding to rates ranging from 3 to 7 times the average baseline operant level. Females reached a mean peak of 5.5 times their initial operant rate after 20 minutes of training, while males reached a mean peak of 3.1 times their initial operant rate after 25 minutes of training. However, the sex difference for total number of criterion vasocon- 


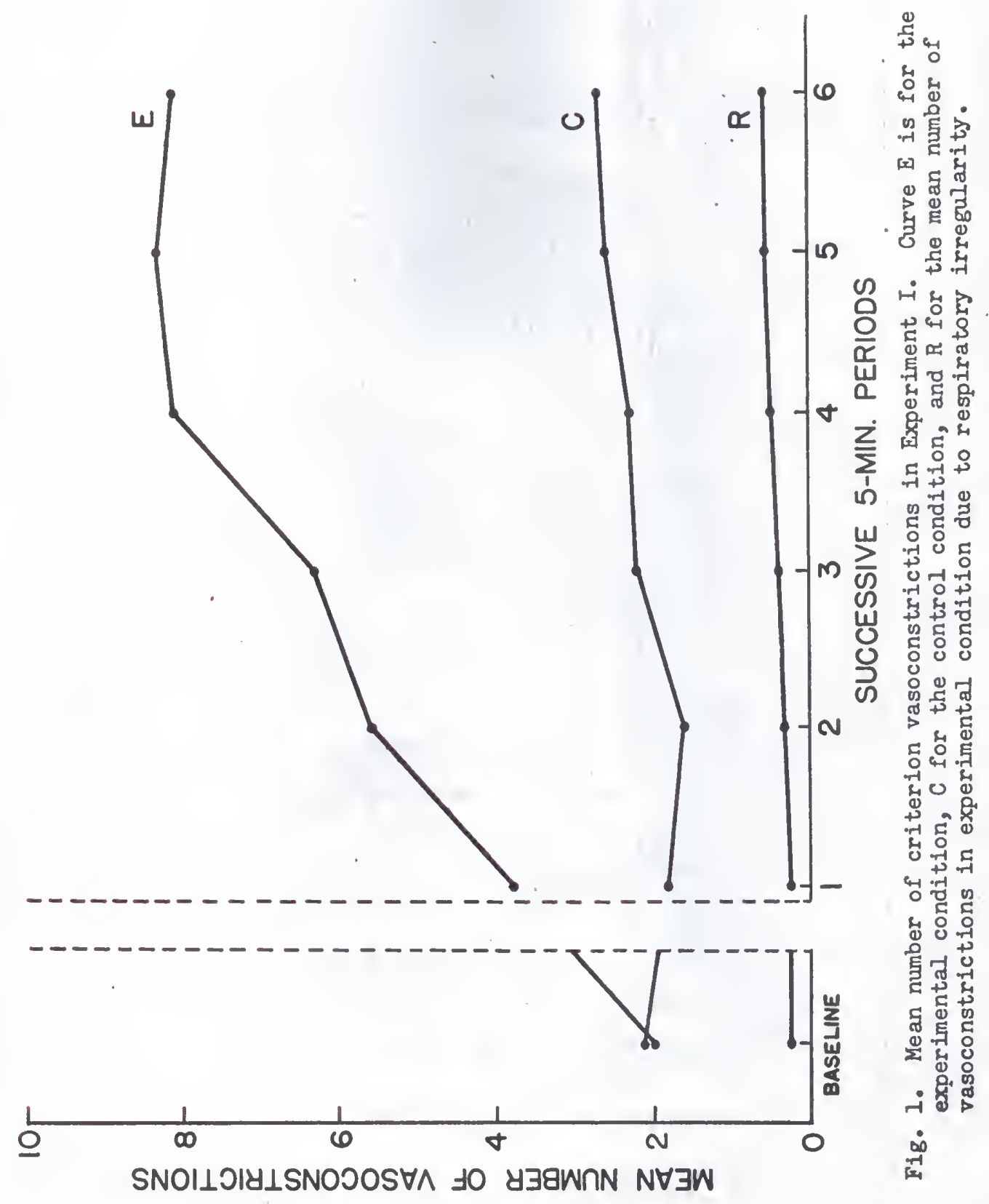


strictions during training was not significant (Mann-Whitney $U=13$, $\mathrm{p}>.50)$

Respiration control. Also shown in Fig. 1 (Curve $R$ ) are the results of an analysis of the effects of respiration upon vasoconstriction. Vasoconstriction invariably occurs each time a deep inspiration is taken and held (Bolton, Carmichael, and Sturup, 1936). A separate record of respiration was not taken in this experiment but small respiratory waves appear in plethysmographic records of finger volume (Burch et al., 1942) and scoreable waves were found in all 12 subjects of Group E, except when possibly obscured during large vasoconstrictions. Analysis of these waves should provide a satisfactory control since vasoconstriction has about a 3-sec. latency and any respiratory irregularity or breath-holding should be easily detectable in the respiratory cycle preceding a vasoconstriction.

A criterion vasoconstriction was scored as a possible respiratory artifact if (1) there was no detectable dip at the expected point assuming a regular respiratory rhythm, or if (2) the respiratory period varied more than $1 \mathrm{sec}$. either for the immediately preceding cycle or during vasoconstriction. It was not possible to analyze irregularities in respiratory amplitude although an amplitude change is usually accompanied by a rate change and respiratory periods were very rarely found to vary more than 1 sec. from mean period for the entire experiment. Possible respiratory artifacts were found to be quite rare and nearly all due to the first criterion listed above during large vasoconstrictions when respiratory waves might be obscured by the superimposed vasomotor wave. The mean number of these possible artffacts are plotted 
in Fig. 1, where it can be seen that Curve $R$ (for Group $E$ only) begins at 0.25 and rises only to 0.58 during the experiment. No cases of breath-holding were found and there were no missing respiratory cycles in the records except during large vasoconstrictions.

Thermal stimuli control. Since peripheral vasomotor activity is normally involved in the temperature regulation of the body, it was necessary to check on possible initiation of vasoconstrictions by the thermal stimuli used in the pseudo-task. The temperature changes were very slow (means of $4.7^{\circ} \mathrm{C} . / \mathrm{min}$. for warming and $1.8^{\circ} \mathrm{C} . / \mathrm{min}$. for cooling), very small (limited to DL which averaged about $1-2^{\circ} \mathrm{C}$. ), and limited to one finger tip, so no effect was expected. In Group $C$ there was a mean of 10 vasoconstrictions during warming and 16 during cooling over the $35 \mathrm{~min}$. of the experiment. However, this difference is due entirely to the fact that, in the loosely controlled pseudo-task, there were 50 per cent more cooling trials than warming trials.

Activation level control. Respiratory rates and pulse rates were scored from the plethysmograph records to see if general autonomic adaptation during training might have contributed to the conditioning effect in Group E. Mean respiratory rate decreased slightly from 16.3 to 15.6 cycles/min. Mean pulse rate increased slightly from 84.0 to 85.9 beats/min. However, neither of these changes were significant ( $p>.05)$ by the Binomial Sign Test, indicating that general autonomic levels remained stable.

Discussion

The main results are clear-cut; the operant procedure resulted in a significant increase in number of vasoconstrictions. Moreover, this 
increase does not appear to have been mediated by gross skeletal muscle activity. The analyses appear to rule out both respiration and gross movements of the hand. Since the hydroplethysmograph is quite sensitive to movement artifacts, any movements of other parts of the body large enough to produce vasoconstriction should also have been detected if they had been present.

Inspection of the results also suggests that the temperature changes included in the pseudo-task did not affect the results. In addition, there was no difference in this regard in method between experimental and control conditions.

The method does not permit verbal mediation to be entirely ruled out; on the other hand, no vasoconstrictions that followed within six seconds the subjects' verbal reports were scored. Furthermore, although some verbal responses were reinforced, in neither condition did the frequency of such verbal responses increase as training progressed.

\section{Experiment II}

The results of Experiment I were inconclusive for several reasons. The type of criticism that Church (1964) has made of yoked experimentalcontrol designs applies to the present design, although in a unique way. Church's main point is that when experimental and control subjects are paired and run simultaneously, and the experimental subject receives contingent reinforcement while his control receives the same reinforcement but non-contingent upon his responses, and these latter reinforcements produce artifactual responses which are then subsequently excluded from the analysis; then, a bias is introduced into the results 
which favors conditioning performance of the experimental group. This is because reinforcements are given to experimental subjects just after their responses, when response probability is lowest, while non-contingent reinforcements are given control subjects when their response probability is much higher.

In the design of Experiment I, the possibility of introducing this kind of bias was even magnified: control subjects received reinforcements contingent upon their non-response when probability of responding would obviously be at its highest point. Elimination of all responses to the reinforcement from the results of both groups would then exclude many more artifactual responses from control than from experimental data. Fortunately in that experiment, the reinforcement conditions were such that there were no such vasoconstrictions, of criterion amplitude to the signal light, that had to be excluded from the results of either group. In fact, for the control subjects there were more vasodilatations (mean of 28.8 ) than vasoconstrictions (mean of 11.1 ) to the light. In addition, it can be noted in Fig. I that the control curve drops slightly (but not significantly), rather than rises, when the reinforcement was introduced following the baseline condition (in which neither group received reinforcement).

However, one could point out that the criterion vasoconstrictions following verbal responses were excluded from the results, which would then be biased if control subjects produced an increasing number or a greater number of these overall than experimental subjects. However, the data were in just the opposite direction; in Group C, the total number of excluded responses began at 17 and decreased slightly to 4 
at the end of training, while in Group E, the total number of excluded responses began at 16 and increased to 36 by the end of training. Consequently, omitting these artifacts could have led only to a bias against group differences, on the basis of Church's argument.

The control measures on respiration and skeletal muscle activity were gross, depending on artifactual components of the plethysmogram. However, in this connection, it can be noted that the vasoconstriction criterion was comparably gross: the amplitude of response had to be about 90 per cent, on the average, of constrictions in the baseline period to count. Thus, the method missed both small respiratory irregularities and also their resulting vasoconstriction reflexes.

In regard to other subtle skeletal muscle activity, on the other hand, the interpretation is on unsafe ground. A study by Neumann, Lhamon, and Cohn (1944) suggests that skeletal muscle tension may be inversely related to vasomotor tone (as indicated by pulse volume amplitude) in the extremities. This means in the present procedure that the frequency of large vasoconstrictions could increase merely because of increasing relaxation of subjects during the training. The slightly increasing mean heart rate found for Group $\mathrm{E}$ suggests otherwise, but only a direct measure of skeletal muscle tension by electromyographic (EMG) recording could verify this assumption.

In addition to these refinements, it also was desirable to eliminate the subjects' pseudo-task so as to do away with thermal stimulation of the finger and with verbal reports along with their associated vasoconstrictions. This required a marked alteration of the instructions to enlist the subject's cooperation in attending to the signal 
light and in controlling his movements, muscular tension, and breathing irregularities.

Finally, it was desirable to include an extinction procedure, to determine if the difference between the experimental and control conditions remained when reinforcement was omitted.

Method

Design. The basic design involved five independent groups of subjects: two experimental groups, two control groups, and one baseline control group. For certain statistical analyses, sex was included as an additional variable.

The two experimental groups (EC and EN) were treated alike during acquisition, with each vasoconstriction followed by reinforcement. During extinction, reinforcement was omitted entirely for Group EN,' while for Group EC a counter-conditioning procedure was employed, with reinforcement contingent upon failure to exhibit vasoconstriction.

The two control conditions were matched to Groups EC and EN as in Experiment I, and were treated identically during both the acquisition and the extinction phases. During the acquisition phase, reinforcement was contingent upon failure to exhibit vasoconstrictions; during the extinction phase reinforcement was entirely omitted.

The baseline control group (B) received no reinforcement at any time.

Subjects. A total of 54 students from introductory psychology classes were used, 6 males and 6 females in each of the two experimental and the two control groups, and 3 males and 3 females in the final group (B). The data of 7 subjects ( 3 males, 4 females) were excluded 
and replaced either because of an equipment failure $(n=2)$ or because of excessive movement $(n=5)$.

Experimental subjects were assigned to extinction condition according to a predetermined random order. A matched control subject was run as soon as the number of reinforcements per period for each experimental subject had been determined.

Apparatus. Right index finger volume was recorded from a Yellow Springs-Fels plethysmograph on one channel of a Beckman-Offner Model $R$ Dynagraph oscillographic recorder at $2.5 \mathrm{~mm} . / \mathrm{sec}$. speed with a Type 9806A AC/DC Input Coupler (set for DC). The electronically controlled heater of the finger cup was modified to DC operation to eliminate 60cycle interference to EMG recording, and cup water temperature was held to within $0.5^{\circ}$ of $35^{\circ} \mathrm{C}$.

Right forearm extensor-flexor EMG was recorded on a second oscillograph channel using a Type 9852 EMG Integrator Input Coupler modified to $0.25 \mathrm{sec}$. rise and $1.0 \mathrm{sec}$. decay time constants. The EMG electrodes were two standard EKG arm electrodes ( $32 \times 55 \mathrm{~mm}$.) plus a third similar electrode for ground (placed on the forearm near the elbow). Sanborn Redux paste was applied to the electrodes, which were held in place lightly with standard arm straps. Preliminary tests indicated that placement of the two active electrodes for maximal EMG from isometric extension and flexion of the index finger also gave a measureable indication of any movement or muscle tension great enough to produce a finger vasoconstriction or to affect vasomotor tone (as indicated by finger pulse volume amplitude). The oscillographic recorder at maximum sensitivity had a sine-wave frequency response of 50 to $1700 \mathrm{cy} \cdot / \mathrm{sec}$. (at $50 \%$ down) and a nonlinear calibration from 1 to 50 microvolts peak-to- 
peak, in terms of equivalent sine-wave input at $500 \mathrm{cy} . / \mathrm{sec}$.

Abdominal and thoracic respiration were recorded on the third and fourth oscillograph channels with Type 9806A AC/DC Input Couplers (set for $D C$ ) from mercury-in-rubber strain gages around the trunk at the xiphoid and under-arm levels. Each gage operated in a full bridge resistance circuit powered by a mercury cell. The gages were made up according to Ackner's (1956) description except for the use of pure silver electrodes which are much more stable with mercury than stainless steel electrodes.

The reinforcement light was a standard pilot light assembly with translucent plastic dome and incandescent lamp (\#49) operated at 0.1 watt (DC). This light was turned on by the experimenter's manual switch, recorded on the marker channel of the oscillograph, and turned off after 3 sec. by a Hunter timer. The light was located on a small sloping panel $\left(9 \times 13^{\prime \prime}\right)$ on the front of the subject's desk chair, which also served as a rest for the right arm and plethysmograph cup.

The $15 \times 20^{\prime}$ subject's room was normally lighted, sound-treated (for $60 \mathrm{Db}$. attenuation of external noise), and electrostatically shielded by grounded copper screening in the walls, ceiling, and floor. The only equipment located in this room was the plethysmograph hydraulic unit, an intercom, and a loudspeaker for about $60 \mathrm{Db}$. sound level of white masking noise. There was no electrical interference to EMG from any inside or outside source except from the remote-controlled motor that adjusted the water level in the plethysmograph standpipe and this was not operated during the experimental recording. 
Procedure. The experimental procedure was similar to that for Experiment I. Immediately after a 5 minute baseline period in which no reinforcement was administered, there was a 25 minute acquisition period, followed by a 10 minute extinction period. Subjects received only the initial instructions and there were no rest periods.

The experiment was given the title of "a study of involuntary reactions." The subject was shown into the experimental room, seated in the desk chair, and given the following instructions:

This is an experiment in learning. We are attempting to condition an involuntary response over which you have no direct control. I will attach pickups to your finger, arm, and trunk to record various activity. In no case will you receive an electric shock or other unpleasant stimulus. All you have to do is watch the signal light that indicates when you are making the correct response. But don't try to make any kind of voluntary response. Just sit in a comfortable position, relax, breath quietly and evenly, and don't make any unnecessary movements. This will take 40 minutes, so if you get uncomfortable and have to move, go ahead and change position but don't keep moving around any longer than necessary. It is necessary for you to stay awake. If any of the equipment slips or you become uncomfortable you can call me over the intercom, which is on all the time. Do you have any questions?

The instructions to Group B (baseline condition throughout) were the same except for omission of reference to the signal light and correct response. In no case was there any mention of the initial fiveminute baseline period or the final 10-minute extinction period.

No light reinforcement was given in the baseline period. In the second to sixth periods ( 25 minutes total) which followed immediately after the baseline period, experimental subjects received the reinforcement light immediately upon the termination of a definite vasoconstriction (no amplitude criterion was estimated as in Experiment I). No attempt was made to selectively reinforce only those vasoconstrictions that were not associated with respiratory or EMG changes. All 
constrictions were reinforced unless preceded by bodily movement. In the seventh and eighth periods (10 minutes total), no reinforcement was given subjects assigned to Group EN while those in Group EC continued to receive signals at about the same rate as before but contingent upon five seconds of minimal vasomotor fluctuation. Each subject in either of the control (C) groups received the same number of reinforcements per five-minute period as his matched experimental subject had received during the 25 -minute acquisition condition, but contingent upon five seconds of vasomotor stability. Reinforcement was omitted for all control subjects during the extinction condition.

Subjects in Group B were treated throughout just as in the baseline period.

Following the experiment, the subject was interviewed for his report of any event or behavior related to the onset of the signal light and for any specific awareness of changes in the finger.

Scoring. The amplitude of all measureable decreases in finger volume was scored so as to exclude the respiratory component by measuring the vertical distance between the beginning and end of the decrease at corresponding points (phase) in the respiratory cycle. The cardiac component was excluded from vasomotor scoring by measuring along the troughs of the pulse waves of the plethysmogram. Any decreases beginning during the interval of 2 to 5 seconds after the onset of the light were marked. In addition, all volume changes beginning within or in progress during the interval of 2 to 5 seconds after onset of the light. were scored, including increases in finger volume.

Any abrupt fluctuation of the plethysmogram, due to the slightest 
movement of the finger, was excluded from amplitude scoring. The amplitude was scored as "?" if a movement completely disrupted the volume baseline or threw the pen off scale, and any vasoconstrictions 2 to 5 seconds immediately following such movement artifact were noted.

The amplitude criterion of vasoconstriction was individually set for each subject to give an operant level for the baseline period of two vasoconstrictions free of preceding or concurrent skeletal muscle artifact either in the plethysmogram or EMG channels. This criterion method was similar to that of Experiment I and appeared to be necessary in order to equate subjects on initial operant level, regardless of recording sensitivity, total finger volume within the plethysmograph cup, and other instrumental variables and individual differences associated with absolute volume measurements. An amplitude cut-off point also eliminates the minute volume changes that may not be vasomotor (e.g., heart rate and stroke volume, blood pressure changes, etc.) and the unreliability in scoring these small fluctuations.

The amplitude criteria set in the above manner provided results comparable to Experiment I and the difference between means for the experiments $\left(I=1.66\right.$, II $\left.=1.67 \mathrm{cu} . \mathrm{mm}_{\bullet}\right)$ and between conditions for Experiment II $(E=1.66, C=1.68)$ were negligible.

Due to ties within subjects, it was not always possible to select a criterion that would give a baseline operant level of 2.0 . However, the differences between group means in this respect were negligible $(E=2.00, C=1.96, B=1.83)$.

With the original intention of removing by means of analysis of covariance the vasomotor reflex component due to variable respiratory am- 
plitude (e.g., deep inspiration: Bolton et al., 1936), the inspiratory amplitudes preceding and concurrent with each vasoconstriction were scored on 12 experimental subjects. However, this scoring was discontinued when it was noted that intraindividual correlations between concurrent/preceding inspiratory amplitude ratios, or between concurrent inspiratory amplitudes alone, and vasoconstriction amplitudes were very low and many respiratory irregularities occurred that were not quantifiable in terms of a single measure. In view of these difficulties, together with the complication of adaptation in the respiratory reflex (Royer, 1966), this scoring was abandoned and any vasoconstriction occurring within five seconds after a thoracic or abdominal respiratory irregularity was simply tabulated separately and excluded from the main results.

As a general activation level index, tonic respiratory rate was sampled over a one-minute period during the first such interval in each five-minute period that was free of gross respiratory irregularities. The number of cycles was counted to the nearest half cycle.

The integrated EMG records were first carefully inspected in relation to concurrent and succeeding vasomotor activity. Scoring of phasic EMG activity was discarded because not a single clear case of a scoreable vasomotor reflex to skeletal muscle activity was discovered. That is, no effect upon vasomotor activity was noted from single, brief spikes. Either short, large bursts of EMG activity threw the plethysmograph off scale or there was moderate but continuous EMG phasic activity which was related to moderate irregularities (usually completely unscoreable) in the plethysmograph record. Thus, the hydroplethys- 
mograph was more sensitive to muscle artifact than was EMG recording. Only tonic EMG levels were scored. A 10-second average level was measured with a non-linear scale of microvolts, sampled at the beginning of each minute.

It was not expected that heart rate (HR) could be precisely measured beat to beat since the recording speed was only $2.5 \mathrm{~mm} . / \mathrm{sec}$. and no cardiotachometer channel was employed. However, the period of five $\mathrm{HR}$ intervals immediately preceding and again concurrent with non-respiratory vasoconstrictions were sampled in the experimental records in the baseline period and also in the next to last acquisition period. In all subjects, the tendency was for cardiac deceleration following I to 4 seconds the beginning of a non-respiratory vasoconstriction. Therefore, the period of the five slowest HR intervals in finger pulse volume during the vasoconstriction was measured to the nearest 0.1 sec. $(0.25 \mathrm{~mm}$. on the record). For comparison, the period of the Immediately preceding five $\mathrm{HR}$ intervals was also measured.

Heart rate level was also sampled as an index of general activation level. The number of $\mathrm{HR}$ intervals was counted over a 30 second interval, taken at the beginning of each five minute period for all subjects.

$\underline{\text { Results }}$

Vasoconstriction conditioning. The mean number of vasoconstrictions of criterion amplitude per five-minute period for the experimental, control, and baseline groups are plotted in Fig. 2. These are the primary results in graphic form, with the exclusion of vasoconstrictions related to respiratory irregularity and of vasoconstrictions following 


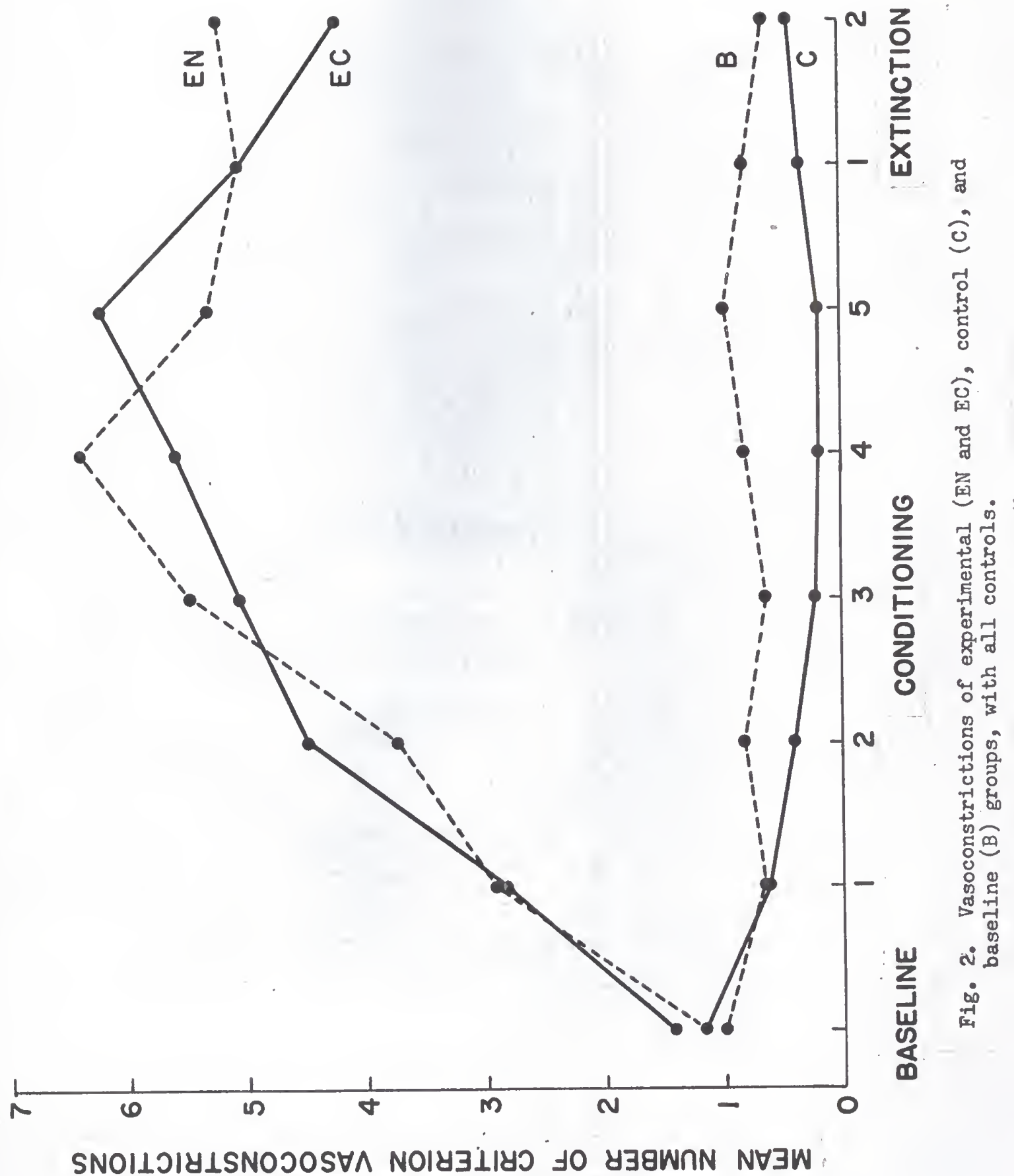


two to five seconds the onset of the reinforcement light, which were analyzed separately. The mean number of vasoconstrictions for Group EC began at a baseline level of 1.42 and reached a peak of 6.25 after 25 minutes of conditioning. The mean for Group EN began at a baseline level of 1.17 and reached a peak of 6.42 after 20 minutes of conditioning. Subjects under the control condition, on the other hand, began at a mean baseline level of 1.12 and decreased to 0.21 after 20 minutes of control reinforcement. The mean performance of the baseline group was more irregular but appeared to vary randomly about a mean frequency of 0.83 .

The control data included so many zero scores following the initial baseline period that analysis of variance was out of the question. However, of the 15 subjects showing any change at all from baseline to the fourth reinforcement period, 14 are in the negative direction. Discarding zero cases, this shift was significant $(p=.002$, two-tailed Binomial Sign Test). Also, the overall difference between Groups $C$ and $B$ during conditioning was significant $(t=2.71,28$ df, $p<.02)$.

The differences between experimental and matched control conditions were very pronounced. In the third acquisition period (following 10 minutes of conditioning), 23 of 24 subjects in Groups EC and EN exceeded the number of vasoconstrictions of their matched subjects in Group C, and this included all 24 in the final two periods.

However, in the analysis of variance described below, both the control and baseline groups were excluded. This choice was made rather than using E - C difference scores so that the analysis of the experimental results would be free of counter-conditioning effects in the con- 
trol condition.

The summary of a $2 \times 2 \times 5$ factorial analysis of variance, with repeated measures on one factor (Winer, 1962, p. 337), for acquisition of Groups EC and EN is presented in Table 1. The trend and interaction variances were further analyzed into linear, quadratic, cubic, and quartic components, using orthogonal polynomial coefficients (Winer, 1962, p. 353). The linear component of the conditioning trend over the five reinforcement periods was highly significant and accounted for 88 per cent of the variance across periods. The quadratic component of the trend was also significant and accounted for 12 per cent of the trend variance.

The factor of sex was, of course, a portion of the between subjects variance and was insignificant. Individual subjects gave peak frequencies from 1 to 16 per period, corresponding to 0.8 to 12.3 times the mean baseline operant level. Males gave a mean peak performance 4.2 times their mean baseline level after 20 minutes of training, while females gave their first peak after 15 minutes of training at 5.4 times their mean baseline level. The fact that the female group gave two peaks, one in the third and another of nearly equal magnitude in the fifth conditioning period, would account for the nearly significant $\mathrm{S} \times \mathrm{P}$ interaction $(.10>\mathrm{p}>.05)$. This bimodality of the female group learning curve was an artifact of combining early and late conditioners since it was not observed within subjects.

Vasoconstriction extinction. The main extinction results also appear in Fig. 2. As can be noted, under the EN condition with complete omission of reinforcement, mean performance remained at the same level 
Table 1

Summary of Analysis of Variance of Sex (S), Extinction Condition (C), and Trend over Acquisition Periods (P) in Groups EC and EN of Experiment $\Pi$.

\begin{tabular}{|c|c|c|c|}
\hline Source & $d f$ & Mean Square & $\mathrm{F}$ \\
\hline S & 1 & 36.3000 & 1.153 \\
\hline C & 1 & 0.0333 & 0.001 \\
\hline$S \times C$ & 1 & 10.8000 & 0.343 \\
\hline Error (between) & 20 & 31.4833 & \\
\hline $\mathbf{P}$ & 4 & 39.8000 & $12.635 * * *$ \\
\hline$P_{\text {lin }}$ & 1 & 139.5375 & $44.298 * * *$ \\
\hline$P_{\text {quad }}$ & 1 & 18.5744 & $5.897 *$ \\
\hline$P_{\text {cubic }}$ & 1 & 1.0667 & 0.339 \\
\hline Pquart & 1 & $0.0214_{4}$ & 0.007 \\
\hline $\mathrm{S} \times \mathrm{P}$ & 4 & 4.8000 & 1.524 \\
\hline$S \times P_{l i n}$ & 1 & 0.2042 & 0.065 \\
\hline$S \times P_{\text {quad }}$ & 1 & 2.1696 & 0.689 \\
\hline$S \times P_{\text {cubic }}$ & 1 & 8.8167 & 2.799 \\
\hline$S \times P_{\text {quart }}$ & 1 & 8.0095 & 2.543 \\
\hline$C \times P$ & 4 & 3.8667 & 1.228 \\
\hline$C \times P_{1 \text { in }}$ & 1 & 0.0375 & 0.012 \\
\hline$C \times P_{\text {quad }}$ & 1 & $3.2411-$ & 1.029 \\
\hline$C \times P_{\text {cubic }}$ & 1 & 12.1500 & 3.857 \\
\hline$C \times P_{\text {quart }}$ & 1 & 0.0381 & 0.012 \\
\hline $\mathrm{S} \times \mathrm{C} \times \mathrm{P}$ & 4 & 1.1333 & 0.360 \\
\hline $\mathrm{S} \times \mathrm{C} \times \mathrm{P}_{1 \text { in }}$ & 1 & 0.7042 & 0.224 \\
\hline $\mathrm{S} \times \mathrm{C} \times \mathrm{P}_{\text {quad }}$ & 1 & 2.5030 & 0.795 \\
\hline$S \times C \times P_{\text {cubic }}$ & 1 & 0.0667 & 0.021 \\
\hline$S \times C \times P_{\text {quart }}$ & 1 & 1.2595 & 0.400 \\
\hline Error (within) & 80 & 3.1500 & \\
\hline
\end{tabular}

$* * * p<.001$

$* \mathrm{p}<.05$ 
as at the end of acquisition; but under the EC condition with reinforcement of no-response during the extinction phase, mean performance began to drop abruptly. Omission of no-response reinforcement of control subjects during their extinction condition produced a slight increase in mean frequency of vasoconstrictions, but this tendency was not statistically significant.

The summary of a $2 \times 2 \times 3$ factorial analysis of variance, with repeated measures on one of the factors during the experimental extinction condition, is presented in Table 2. The trends were analyzed over three periods, the final reinforcement period in addition to the two extinction periods. There was a significant linear component accounting for 96 per cent of the trend variance. Since the $C \times P$ linear interaction was significant, the linear trend variance was further analyzed into EC and EN effects. Only the EC trend effect ( $P_{1 i n}$ in Table 2) was significant.

There was no need to test the significance of the very large difference between Group C and either Group EC or Group EN since all 24 experimental subjects exceeded the performance of their matched controls during extinction.

There was a tendency $(.10>\mathrm{p}>.05)$ for linear interaction between sex and extinction trend which favored females. In the female EC group, 5 subjects decreased while the sixth showed no change with shift of reinforcement to no-response.

Vasomotor response to reinforcement. During conditioning, experimental subjects made a total of 51 .vasoconstrictions of criterion amplitude beginning 2 to 5 seconds following the onset of light. These 
Table 2

Summary of Analysis of Variance of Sex (S), Extinction Condition (C), and Trend over Extinction Periods (P) in Groups EC and EN of Experiment II.

\begin{tabular}{|c|c|c|c|}
\hline Source & $d f$ & Mean Square & $F$ \\
\hline $\mathrm{S}$ & 1 & 13.3472 & 0.548 \\
\hline $\mathrm{C}$ & 1 & 0.0139 & 0.001 \\
\hline$S \times C$ & 1 & 13.3472 & 0.548 \\
\hline Error (between) & 20 & $24 \cdot 3583$ & \\
\hline $\mathrm{P}$ & 2 & 6.7916 & 2.555 \\
\hline$P_{\text {Iin }}$ & 1 & 13.0208 & $4.898 *$ \\
\hline $\mathrm{P}_{\operatorname{lin}_{\mathrm{EC}}}$ & 1 & 24.0000 & $9.028 * *$ \\
\hline$P_{\text {lin }}$ & 1 & 0.0417 & 0.016 \\
\hline$P_{\text {quad }}$ & 1 & 0.5625 & 0.212 \\
\hline$S \times P$ & 2 & 6.4306 & 2.419 \\
\hline$S \times P_{\text {lin }}$ & 1 & 9.1875 & 3.456 \\
\hline $\mathrm{S} \times \mathrm{P}_{\text {quad }}$ & 1 & 3.6736 & 1.382 \\
\hline$C \times P$ & 2 & 5.5139 & 2.074 \\
\hline $\mathrm{C} \times \mathrm{P}_{\mathrm{Iin}}$ & 1 & 11.0208 & $4.1146 *$ \\
\hline$C \times P_{\text {quad }}$ & 1 & 0.0069 & 0.003 \\
\hline$S \times C \times P$ & 2 & 1.0972 & 0.413 \\
\hline$S \times C \times P_{\text {lin }}$ & 1 & 0.1875 & 0.071 \\
\hline$S \times C \times P_{\text {quad }}$ & 1 & 2.0069 & 0.755 \\
\hline Error (within) & 40 & 2.6583 & \\
\hline
\end{tabular}


were excluded from the main conditioning results because they were respondents rather than operants. However, they were evenly distributed across periods and their inclusion would merely have the effect of raising the entire EC and EN curves of Fig. 2.

Fig. 3 shows some interesting incidental results of a further analysis of vasomotor responses to light. The lower curves are for experimental and control amplitude means of vasoconstriction and vasodilatation (algebraically summed), whichever response began 2 to 5 seconds after the onset of light. In Curve $C$ it can be seen that there was only an initial adaptation. However, in Curve $E$ there was initial adaptation followed by continuing adaptation to the point of a mean vasomotor balance toward more frequent and larger vasodilatations (values below zero on the ordinate) over constrictions (values above zero on the ordinate) to the light in the fourth conditioning period. The balance toward constriction to the light again occurred during extinction for Group EC (the only group receiving light signals during extinction) when the condition of reinforcement was shifted from response to no-response contingency.

The criterion amplitude means for Group $E$ and Group $C$ are shown as horizontal lines in the upper part of Fig. 3, for comparison with the mean amplitudes of vasomotor response to light. The latter seldomly exceeded one-fourth of criterion vasoconstriction, and then only when a change in conditions was introduced.

Respiratory control and conditioning. Fig. 4 gives the results of an analysis of vasoconstrictions associated with respiratory irregularity which were excluded from the main vasomotor conditioning analysis. 


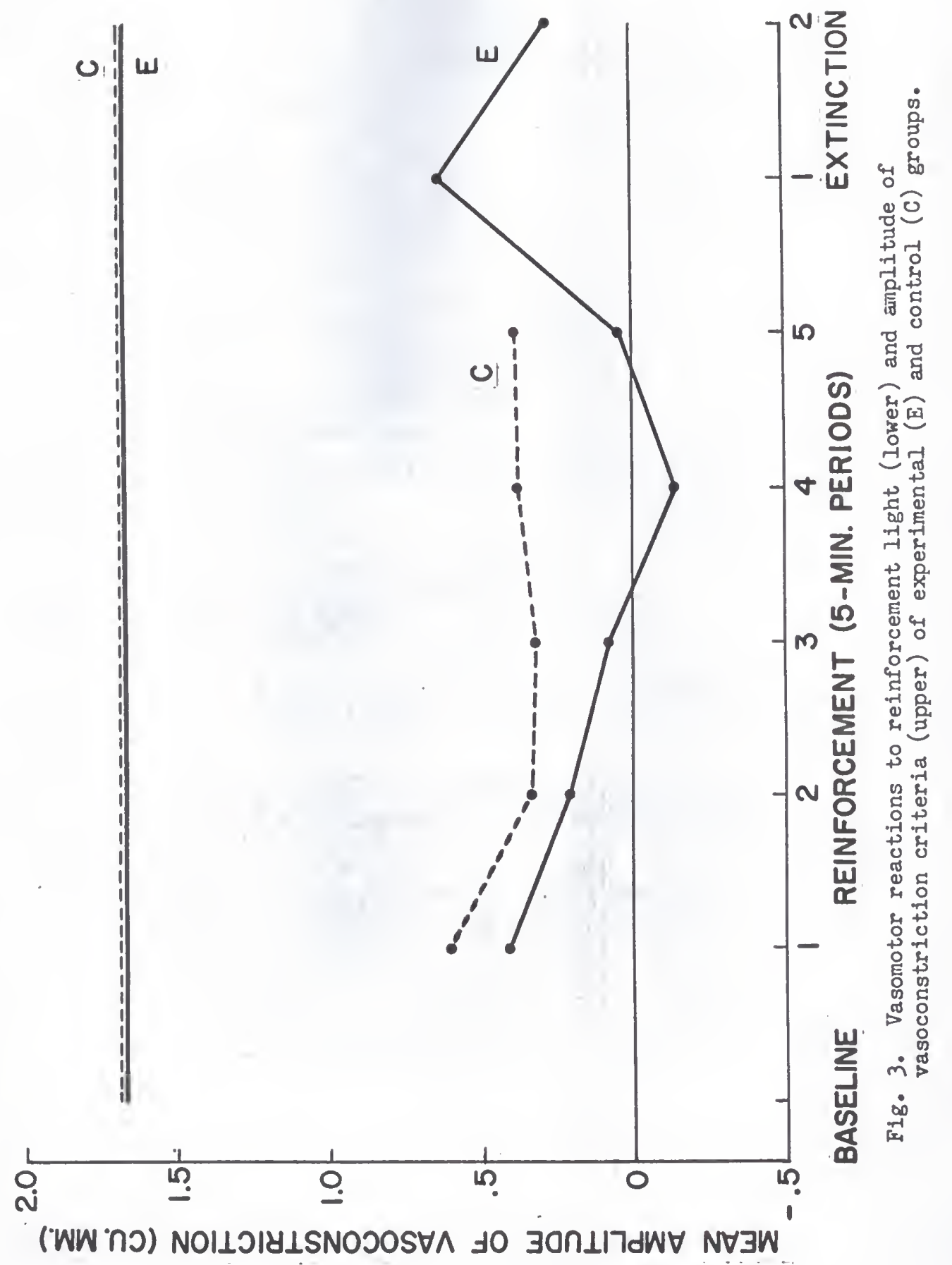




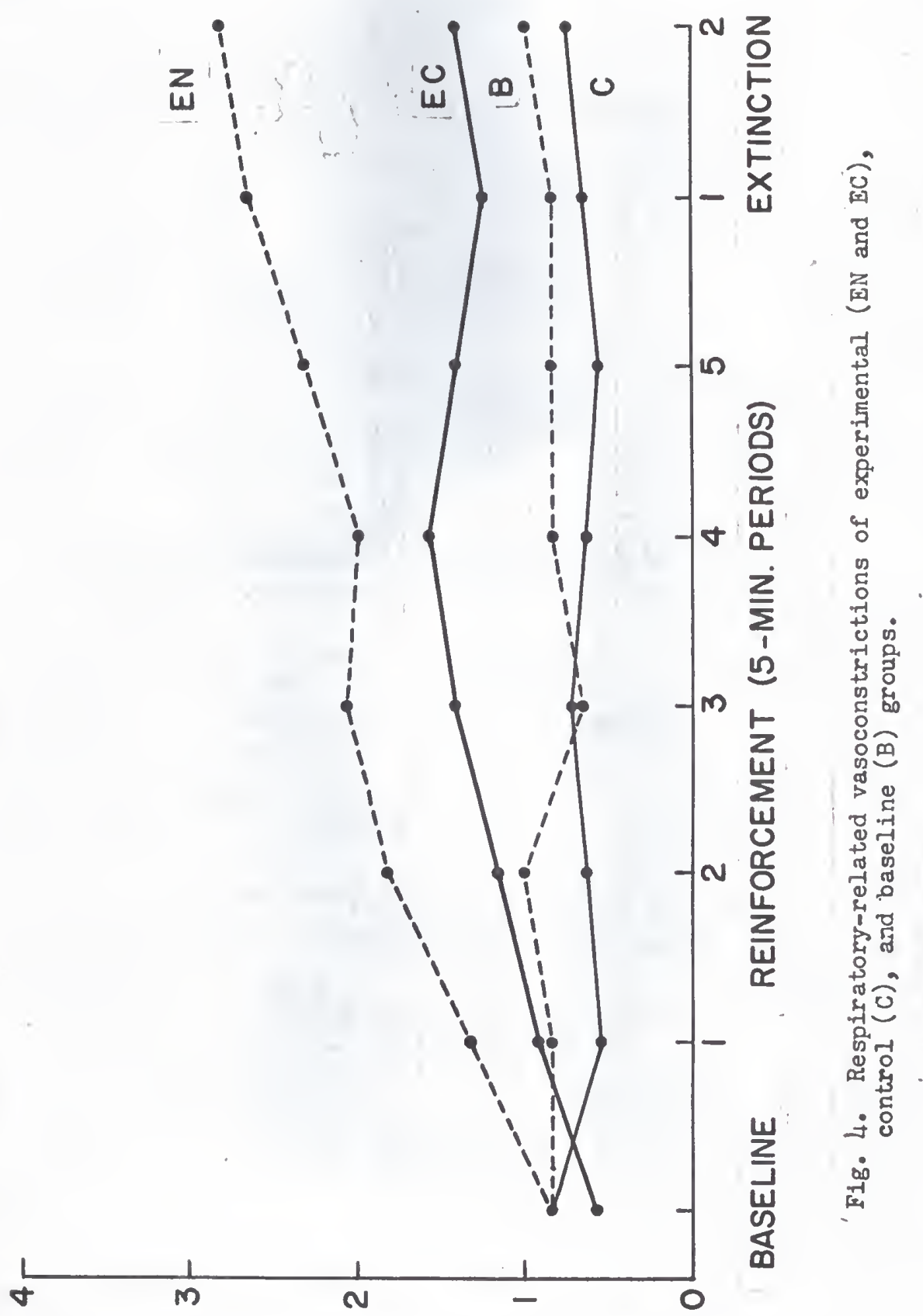

SNOILJIYLSNOJOS $\forall A$ JO ON NVJW 
The curves for Groups B and C remained essentially level, while the curves for both Group EC and Group EN rose during the first half of conditioning, and for Group EN during extinction.

First, it can be noted that exclusion of these data from the main results had the desired consequence of eliminating artifacts that would tend to inflate the main effect.

Second, there appears to have been a conditioning effect in the respiratory-involved vasoconstrictions themselves (which were indiscriminately reinforced during conditioning). The cell frequencies for subject by period were too low for a statistical test of experimental trend, but a simple comparison between experimental subjects and their paired control subjects indicated a very significant difference during conditioning overall ( $p<.001$ by Binomial Sign Test). The mean for Group E was 8.0 and the mean for Group $C$ was 3.1 during conditioning overall, while there was obviously no initial difference (baseline period in Fig. 4). Since these respiratory-involved vasoconstrictions also included virtually all cases of respiratory irregularity that occurred, this result indicates that significant positive conditioning of respiratory irregularity (by coincidental reinforcement) took place in the experimental group.

EMG control. As mentioned in the section on scoring method, no scoreable case of reflexive vasoconstriction to phasic EMG activity was detected. The tonic EMG means for Groups $E$ and $C$ are shown in Fig. 5. In Group E, EMG level began at a mean of 5.24 and terminated at a mean of 2.80 microvolts while in Group C mean.level fell from 7.26 to 2.92 . The initial difference was not significant $(\underline{t}=1.65,46 \mathrm{df}, \mathrm{p}>.10)$. 


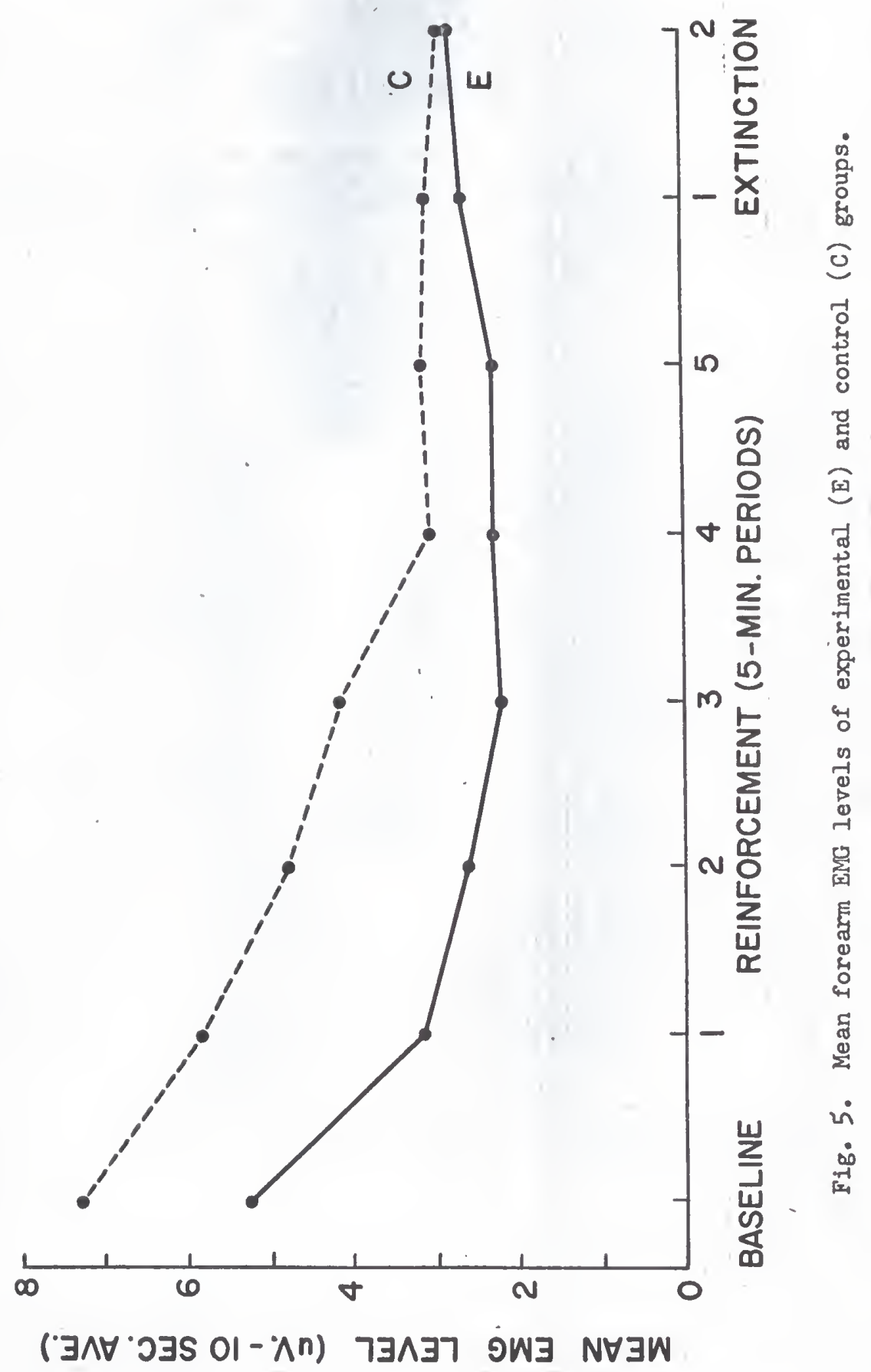


The analysis was not carried further, since the trends were fairly parallel, the control level fell somewhat more than the experimental level (which, if anything, would have biased the main results in the conservative direction), and the levels in both groups during the last part of conditioning and extinction were very low and close to the limits of reliable measurement.

General activation level control. Respiration rates for Groups E and $\mathrm{C}$ are shown in Fig. 6. There was a tendency for both groups to rise but only 13 subjects in Group $E$ and 11 subjects in Group $C$ showed a rise from first reinforcement period to second extinction period, shifts that were neither significant within or between groups.

Mean heart rate levels are shown in Fig. 7. No consistent differences between groups were found for this index. These results then suggest that levels of autonomic activity generally remained stable in all groups and the vasomotor conditioning effect was fairly specific. An incidental finding of significant heart rate conditioning, however, is shown also in Fig. 7. All 24 experimental subjects showed an increase in heart-rate deceleration during criterion vasoconstrictions from baseline to fourth conditioning period. In the baseline period, the mean rate for the five beats immediately preceding a vasoconstriction was 80.0 ; this decreased to a mean of $75.0 / \mathrm{min}$. during the five slowest beats after the beginning of vasoconstriction. In the fourth conditioning period (after 20 minutes of conditioning), corresponding values shifted from a mean of 78.8 to a mean of 69.9 . Thus, the mean heart-rate deceleration increased from 5.0 to $8.9 / \mathrm{min}$.

MAS scores. As part of another experiment, the subjects were ad- 


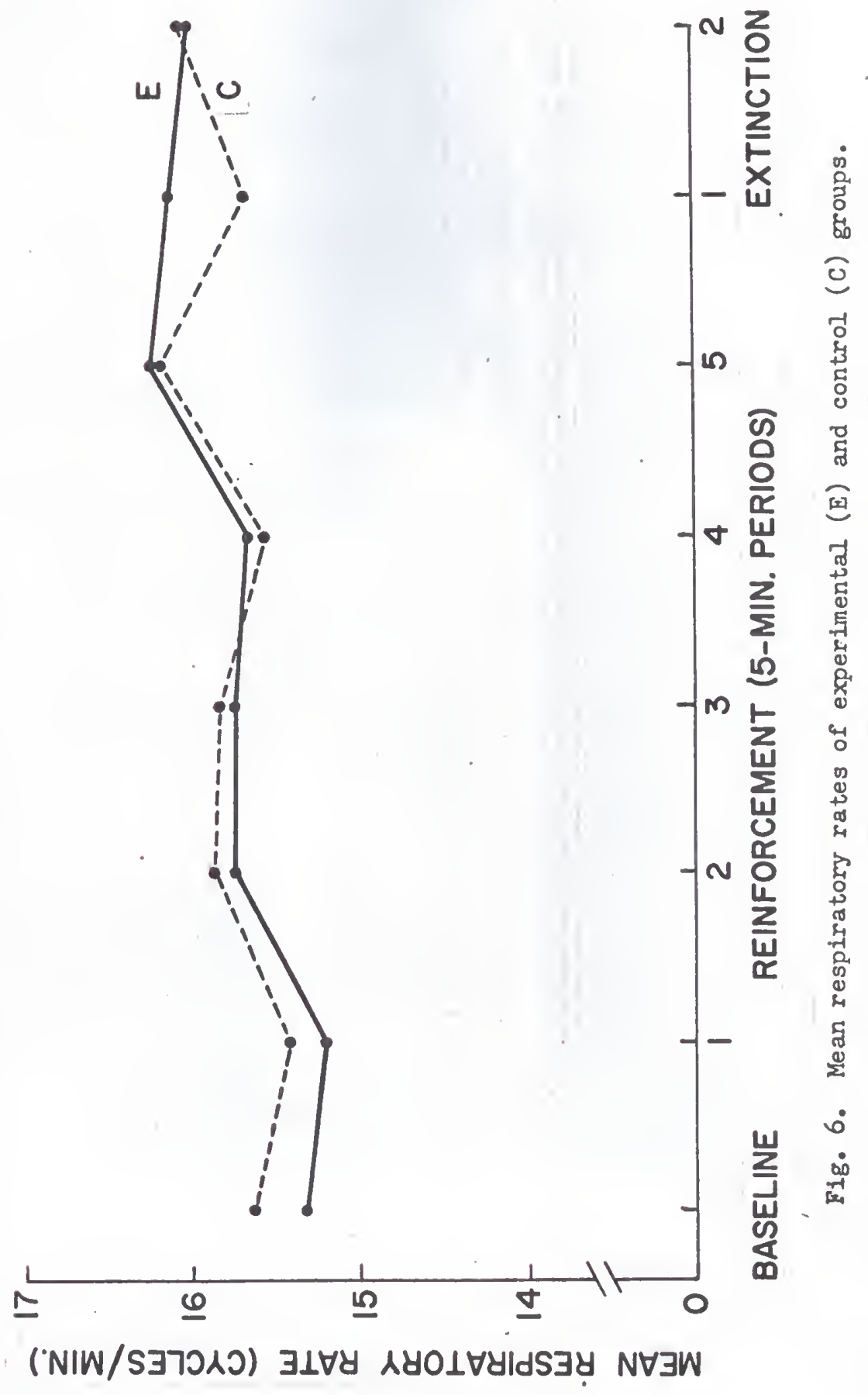




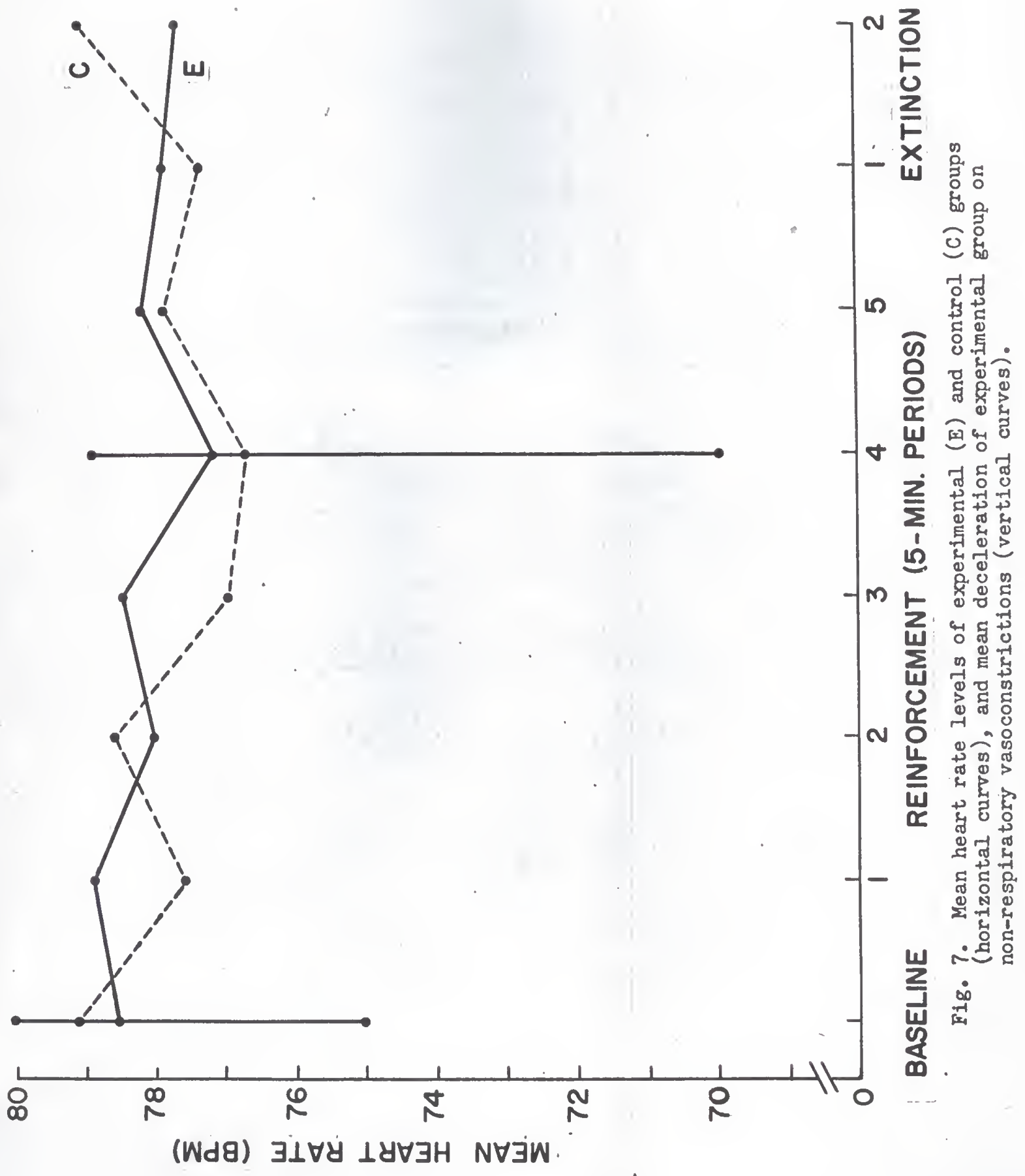


minstered the Taylor Manifest Anxiety Scale in class groups at varying times before or after their participation in the present experiment. Their raw scores ranged from 5 to 38 with a mean of 14.1 for Group E and ranged from 2 to 32 with a mean of 16.6 for Group C. Correlation of these scores with total number of conditioned vasoconstrictions during acquisition for Group E yielded $\underline{r}=+.10$. This value was so low that nothing more was done with these scores.

Interview. A few subjects reported a relation of the light to preceding emotion appropriate to the experimental ("frightening" or "alerting") and control ("maternal") conditions. Six of the experimental subjects reported changes of pressure, tingling, or warmth while control subjects reported only numbness or throbbing in the finger. No other relation of interview reports to vasoconstriction conditioning was observed.

Discussion

The vasoconstriction conditioning of experimental subjects would appear to be independent of skeletal muscle involvement including movement, muscle tension, respiration; and of changes in general activation level. There was a highly significant upward trend in the frequency of vasoconstrictions during experimental conditioning.

During experimental extinction there was a significant downward linear trend for the EC group $(F=9.03, p<.01)$, which received control reinforcement, but not for the EN group, which received no reinforcement during extinction.

On the other hand, the baseline control group, which received no reinforcement throughout the entire 40 minutes, remained essentially at 
initial operant level throughout.

The matched control group showed some counter-conditioning effect from reinforcement of vasomotor stability (no-response contingency). There was also a tendency for Group C to increase in number of vasoconstrictions when reinforcement was omitted.

These control results, together with the "alerting" vasomotor responses given by Group EC to the extinction reinforcement (see Fig. 3) help to clarify the differences between Groups EC and EN during vasoconstriction extinction. Although this result was anticipated before the experiment was begun, the rationale upon which it was based was vague. The EC extinction condition was included because it was possible that complete omission of reinforcement for 10 minutes (Group EN) might dismupt performance and increase vasomotor activity. The results of Group C during acquisition and extinction along with those of Group EC during extinction all support the conclusion that control reinforcement had a counter-conditioning effect. However, this helps in no way to account for the lack of extinction in Group EN.

The simplest interpretation would be that the extinction condition was too brief to produce a decrement in vasoconstriction frequency of Group EN. This is a possibility and it is unfortunate that a longer extinction phase could not be included in the 50 minutes that each subject was available.

Another possibility is that there were no extinction effects in either experimental group and that the apparent counter-conditioning in Group EC was due to the chance assignment of slow conditioners to this group so that their mean performance happened to peak just at the end of 
the conditioning phase. The drop during extinction would then have to be due to interference effects which occurred in both groups but at different times. A $2 \times 2 \times 7$ factorial analysis of variance of sex, extinction, and trend over all reinforcement and extinction periods (Table 3) indeed gave no significant differences or interactions involving EC vs. EN groups. The overall, linear, and quadratic trend components were the only significant results. But a significant quadratic trend is what one would expect from a limited period of conditioning followed by a brief.extinction period. In this analysis, $F=28.58,1 / 120 \mathrm{df}$, $\mathrm{p}<.001$ for $\mathrm{P}_{\text {quad. }}$. For the quadratic trend during conditioning only (Table 1), $F=5.90,1 / 80 \mathrm{df}, \mathrm{p}<.05$. These results, along with the significant extinction trend for Group EC only (Table 2), support the conclusion that counter-conditioning of Group EC produced a highly significant decrement in frequency of conditioned vasoconstrictions. To argue further that this decrement might have occurred without counterconditioning seems to oppose additional evidence. The most relevant result is the fact that Group EN, without counter-conditioning, did not show a significant decrement either before or after extinction was begun. However, it would be desirable in further research to study both conditioning and extinction over longer periods in order to check various extinction effects following a stable asymptote of conditioning. The second experiment replicates the main results of the first experiment very closely. In Experiment II the vasoconstriction conditioning was just as pronounced, and the extinction results support the conclusion that the conditioning effect in both experiments was not due to any bias in exclusion of artifacts in analyzing experimental and control 
Table 3

Summary of Analysis of Variance of Sex (S), Extinction Condition (C), and Trend over Acquisition and Extinction Periods (P) in Groups EC and EN of Experiment II.

\begin{tabular}{|c|c|c|c|}
\hline Source & $d f$ & Mean Square & $\mathrm{F}$ \\
\hline S & 1 & 38.0952 & 0.914 \\
\hline C & 1 & 0.5952 & 0.014 \\
\hline$S \times C$ & 1 & 20.0239 & 0.480 \\
\hline Error (between) & 20 & 41.7024 & \\
\hline$P$ & 6 & 26.8333 & $7.601 *$ \\
\hline$P_{l i n}$ & 1 & 55.4301 & $15.702 * * *$ \\
\hline$P_{\text {quad }}$ & 1 & 100.8934 & $28.580 * * *$ \\
\hline Pcubic & 1 & 0.6944 & 0.197 \\
\hline$P_{\text {quart }}$ & 1 & 3.8961 & 1.104 \\
\hline Residual & 2 & 0.0430 & 0.012 \\
\hline$S \times P$ & 6 & 5.2619 & 1.491 \\
\hline$S \times P_{1 i n}$ & 1 & 1.8229 & 0.516 \\
\hline$S \times P_{\text {quad }}$ & 1 & 8.0005 & 2.266 \\
\hline$S \times P_{\text {cubic }}$ & 1 & 0.0000 & 0.000 \\
\hline$S \times P_{\text {quart }}$ & 1 & 10.6071 & 3.005 \\
\hline Residual & 2 & 5.5704 & 1.578 \\
\hline$C \times P$ & 6 & 3.4841 & 0.987 \\
\hline$C \times P_{1 i n}$ & 1 & 1.8229 & 0.516 \\
\hline$C \times P_{\text {quad }}$ & 1 & 0.6076 & 0.172 \\
\hline$C \times P_{\text {cubic }}$ & 1 & 2.2500 & 0.637 \\
\hline$C \times P_{\text {quart }}$ & 1 & 7.6364 & 2.163 \\
\hline Residual & 2 & 4.2940 & 1.216 \\
\hline$S \times C \times P$ & 6 & 1.2460 & 0.353 \\
\hline$S \times C \times P_{1 i n}$ & 1 & 0.0015 & 0.000 \\
\hline$S \times C \times P_{\text {quad }}$ & 1 & 1.1910 & 0.337 \\
\hline$S \times C \times P_{\text {cubic }}$ & 1 & 4.0000 & 1.133 \\
\hline$S \times C \times P_{\text {quart }}$ & 1 & 0.4773 & 0.135 \\
\hline Residual & 2 & 0.9031 & 0.256 \\
\hline Error (within) & 120 & 3.5302 & \\
\hline
\end{tabular}


data. Therefore, it can be concluded that the operant procedure resulted in the conditioning of the autonomic activity of vasoconstriction in the finger, not mediated by means of skeletal muscle activity. 


\section{Acknowledgment}

Credit for drawing my attention to this experimental problem must go to Dr. Merrill Noble and the research could not have been carried out without his continuing encouragement, guidance, and support.

Dr. Robert C. Haygood has been of great help in clarifying the methodological problems of experimental design and control. And the statistical methods of Experiment II are mainly due to the assistance of Dr. Sam Brown and Gherry Harding.

This investigation was supported in part by Public Health Service Research Grant HD 00956-03, from the National Institute of Child Health and Human Development. 
References

Ackner, B. A simple method of recording respiration. Journal of Psychosomatic Research, 1956, 1, 144-146.

Berlyne, D. E. Conflict, Arousal, and Curiosity. New York: McGrawHill, 1960.

Bolton, B., Carmichael, E. A., \& Stturup, G. Vaso-constriction following deep inspiration. Journal of Physiology, 1936, 86, 83-94.

Burch, G. E., Cohn, A. E., \& Neumann, C. Reactivity of intact blood vessels of the fingers and toes to sensory stimuli in normal resting adults, in patients with hypertension and in senile subjects. Journal of Clinical Investigations, 1942, 21, 655-664.

Church, R. M. Systematic effect of random error in the yoked control design. Psychological Bulletin, 1964, 62, 122-131.

Crider, A., Shapiro, D., \& Tursky, B. Reinforcement of spontaneous electrodermal activity. Journal of Comparative and Physiological Psychology, 1966, 61, 20-27.

Fowler, R. L., \& Kimmel, H. D. Operant conditioning of the GSR. Journal of Experimental Psychology, 1962, 63, 563-567.

Fromer, R. Conditioned vasomotor responses in the rabbit. Journal of Comparative and Physiological Psychology, 1963, 56, 1050-1055.

Kennard, M. A. The cortical influence on the autonomic nervous system. In Bumke \& Foerster (Eds.), Hanbuch der neurologie, Vol. 2. Berlin: J. Springer, 1937, 476-491.

Kimmel, E., \& Kimmel, H. D. A replication of operant conditioning of the GSR. Journal of Experimental Psychology, 1963, 65, 212-213.

Kimmel, H. D., \& Hill, F. A. Operant conditioning of the GSR. Psychological Reports, 1960, $7,555-562$.

Lacey, J. I. The relationship of resting autonomic activity to motor impulsivity. In The Brain and Human Behavior, Proceedings of As- . sociation for Research on Nervous and Mental Diseases, 1958, 36, 144-209.

Lange, G. C. Om Sindsberägelser. Copenhagen, 1885.

Lindsley, D. B. Emotion. In S. S. Stevens (Ed.), Handbook of Experimental Psychology. New York: Wiley, 1951, 473-516. 
Lisina, M. I. The role of orientation in the conversion of involuntary into voluntary reactions. In L. G. Voronin (Ed.), The Orienting Reflex and Exploratory Behavior. Moscow: Academy of Pedagogical Science, 1958.

Neumann, C., Lhamon, W. T., \& Cohn, A. E. A study of factors (emotional) responsible for changes in the pattern of spontaneous rhythmic fluctuations in the volume of the vascular bed of the finger tip. Journal of Clinical Investigations, 1944, 23, 1-9.

Razran, G. The observable unconscious and the inferable conscious in current Soviet psychophysiology: Interoceptive conditioning, semantic conditioning, and the orienting reflex. Psychological Review, $1961,68,81-147$.

Royer, F. L. The "respiratory vasomotor reflex" in the forehead and finger. Psychophysiology, 1966, 2, 24l-248.

Shearn, D. W. Operant conditioning of heart rate. Science, 1962, 137, 530-531.

Shmavonian, B. M. Methodological study of vasomotor conditioning in human subjects. Journal of Comparative and Physiological Psychology, 1959, 52, 315-321.

Skinner, B. F. The Behavior of Organisms: An Experimental Analysis.

New York: Appleton-Century, 1938.

Snyder, C. W. Feedback and perceptual learning. In C. M. Solley and G. Murphy, Development of the Perceptual World. New York: Basic Books, 1960, 244-251.

Sokolov, E. N. Perception and the Conditioned Reflex. New York: MacMillan, 1963.

Solley, C. M., \& Murphy, G. Development of the Perceptual World. New York: Basic Books, 1960.

Winer, B. J. Statistical Principles in Experimental Design. New York: McGraw-HiII, 1962 . 
OPERANT CONDITIONING

OF VASOCONSTRICTION

by

CHARLES WINKLER SNYDER'

B.M.E., University of Wichita, 1951

AN ABSTRACT OF A THESIS

submitted in partial fulfillment of the

requirements for the degree

MASTER OF SCIENCE

Department of Psychology

KANSAS STATE UNIVERSITI

Manhattan, Kansas

1967 
Two experiments were performed to study simple operant conditioning of peripheral vasoconstrictions in humans. In the first, experimental subjects were reinforced with a small "correct" signal light for each criterion vasoconstriction in the right index finger tip, while their matched control subjects received the same number of reinforcements but only following minimal vasomotor fluctuation. Reinforcement was given in the context of a pseudo-task of discriminating and reporting very small and slow temperature changes in the finger cup of the hydroplethysmograph. Excluding vasoconstrictions following verbal reports, the frequency of large vasoconstrictions increased very signi-. ficantly over 30 minutes of conditioning of experimental subjects whereas that of the control group remained essentially at baseline operant level. The effect was well beyond what might have been due to somatic mediation via gross skeletal muscle activity so far as could be determined from movement artifacts and respiratory components in the plethysmograph records.

In the second experiment, a similar method was used except that the pseudo-task and verbal reports were eliminated, and respiration and forearm muscle tension (EMG) were separately recorded. A 10-minute extinction condition was added, with experimental subjects split into two extinction conditions: shift of reinforcement to vasomotor stability (EC) and omission of all reinforcement (EN). Omitting a few UCRs to the reinforcer light, the mean frequency of non-respiratory vasoconstrictions increased very significantly in the experimental groups during conditioning. The performance of the control group, under counter-conditioning, decreased below that of a baseline control group which remained at ini- 
tial operant level throughout 40 minutes with no reinforcement whatsoever. During the extinction phase of 10 minutes, vasoconstriction frequency of Group EC decreased significantly but not that of Group EN. These conditioning and counter-conditioning effects were independent of changes in respiration, muscle tension, skeletal movements, and general autonomic activity lovels. 